\title{
"Con la esperanza de que los P.P. han de volver": Ios esclavos de los jesuitas expulsos bajo la administración laica de Temporalidades (Buenos Aires, 1767-1775)
}

"In the Hope that the Jesuit Priests Will Return": The Slaves of the Expelled Jesuits under the Secular Management of the Temporalities (Buenos Aires, 1767-1775)1

\author{
María Valeria Ciliberto *,**
}

\section{RESUMEN}

Hacia 1767 más de 4.500 esclavos afroamericanos vivían y trabajaban en las propiedades que integraban el vasto patrimonio incautado a la Compañía de Jesús en el Río de la Plata. El frágil equilibrio del sistema esclavista iñiguista fue evidenciado por las investigaciones sobre la gestión de las temporalidades, señalando el fracaso de las Juntas en el mantenimiento/control de la mano de obra forzada. Sin embargo, para el caso de Buenos Aires únicamente se ha estudiado la venta de los esclavos secuestrados en su condición de "bienes muebles". Nuestro trabajo propone reconstruir las decisiones tomadas por la administración laica porteña en relación al tratamiento de esta población e inferir las respuestas que los propios esclavos elaboraron frente a las mismas en el contexto de incertidumbre post expulsión.

Palabras claves: esclavos; jesuitas; temporalidades; Buenos Aires, siglo XVIII.

\section{Abstract}

Around the year 1767 more than 4,500 African-American slaves lived and worked on the properties that comprised the vast patrimony seized from the Society of Jesus on the Río de la Plata. The fragile balance of the Jesuits slave system was evidenced by the investigations on the management of temporalities, pointing out the failure of the Juntas in the maintenance/control of forced labor. However, in the case of Buenos Aires, only the sale of the kidnapped slaves in their condition of "movable property" has been studied. Our work proposes to reconstruct the decisions taken by the secular administration of Buenos Aires in relation to the treatment of this population and to infer the responses that the slaves themselves made to them in the context of post-expulsion uncertainty.

Keywords: slaves; Jesuits; temporalities; Buenos Aires, 18th century.

\footnotetext{
* Universidad Nacional de Mar del Plata, Mar del Plata, Buenos Aires, Argentina.

** Consejo Nacional de Investigaciones Científicas y Técnicas (Conicet), Buenos Aires, Buenos Aires, Argentina. cilibertorodriguez@gmail.com <https://orcid.org/0000-0001-7052-5636>
} 
Mano de obra vital en las explotaciones agrarias y manufactureras de la Compañía de Jesús, pero también importantes en la misión apostólica de la orden, los esclavos de los jesuitas han sido objeto de numerosas investigaciones cuyas distintas perspectivas dialogan con los desplazamientos renovadores de la historiografía más amplia sobre la esclavitud y los afrodescendientes en la hispanoamérica colonial ${ }^{2}$ (Lamborguini; Geler; Guzman, 2017, p. 67-101; Candioti, 2017, p. 95-100).

Para el Río de la Plata, desde las obras pioneras centradas en el funcionamiento económico de sus establecimientos rurales (Morner, 1968; Cushner, 1983), diversas investigaciones reconstruyeron las formas de empleo de la mano de obra servil de la Compañía a fin de destacar la rentable articulación establecida entre los colegios urbanos y sus complejos productivos agrarios. Desde esta perspectiva, se avanzó en el conocimiento de las características demográficas de esta población, sus roles en el proceso productivo y sus vinculaciones con las variadas formas de trabajo libre (Mayo, 1994; AndrésGallego, 1996, p. 231-260; Andrés-Gallego, 2005).

La práctica esclavista de la orden también fue puesta en relación con la ética católica que la inspiraba, vinculando identificaciones y categorizaciones socio-raciales con contextos de prácticas particulares. Se destacó, entonces, la visión espiritualista y el paternalismo jesuita que concebían la integración de sus siervos en el plan de Dios como justificación trascendental del sistema. Desde este enfoque, los análisis de memoriales e instrucciones precisaron las modalidades de control y vigilancia sobre la mano de obra forzada, advirtiendo cómo el trato diferencial de los regulares hacia sus esclavos contribuyó a crear en ellos una cierta identidad y arraigo basados en sentimientos de derechos negados al resto de la población servil. Sugiriéndose incluso la voluntad implícita de desarrollar una esclavitud orientada al surgimiento de comunidades autosuficientes (similares a las reducciones), cuya gestación habría sido interrumpida por el extrañamiento (Troisi Melean, 2012; Tardieu, 2015, p. 17-27).

Las investigaciones sobre la gestión de las propiedades rurales y urbanas incautadas tras la expulsión de 1767 destacaron el fracaso de las administraciones laicas en la manutención y control de los numerosos esclavos que las habitaban y trabajaban. Estos trabajos resaltaron el particular perfil de las dotaciones en relación a la población esclava local, asociaron la eficacia económica del empleo de esta fuerza de trabajo con la articulación complementaria de los establecimientos productivo-mercantiles de la orden y relevaron diferencias en las dinámicas regionales a fin de subrayar los cambios en las lógicas 
económicas de gerenciamiento (Mayo, 1994; Troisi Melean, 1998; Tardieu, 2012). Asimismo, estudios focalizados en las haciendas de Córdoba y las estancias del Paraguay evaluaron el impacto del extrañamiento sobre las condiciones materiales de vida de sus esclavos, vinculando su manifiesto deterioro con las sublevaciones, las fugas y las muertes (Telesca, 2009; Punta, 2016).

Sobre los esclavos de las temporalidades de Buenos Aires, en cambio, se han estudiado únicamente sus perfiles sociodemográficos y las modalidades de su empleo productivo en relación a su distribución intrarregional. También se avanzó en la identificación de las particularidades de su enajenación en su condición de "bienes muebles" (Maeder, 2001; Ciliberto, 2016a). Nuestro trabajo se propone analizar el proceder de la administración porteña en relación a la población servil antes propiedad del Colegio de San Ignacio de Buenos Aires. Para ello reconstruimos las decisiones de los encargados del gobierno de la misma e inferimos algunas de las respuestas elaboradas por los propios esclavos frente a la nueva gestión laica en el contexto de incertidumbre inmediato a la expulsión.

Distintos legajos pertenecientes al fondo Temporalidades de Buenos Aires (Colegio de San Ignacio), Comandancia de Frontera de San Antonio de Areco (Archivo General de la Nación, AGN) y Jesuitas - Argentina (Archivo Nacional Histórico de Chile, ANHCh) constituyen nuestras principales fuentes documentales. Centramos nuestro análisis en los primeros años de la administración laica de estas temporalidades, lapso temporal en el que comienzan las subastas de esclavos por "pieza" y/o "lotes" previas al traspaso masivo de las dotaciones realizado mediante las ventas de las estancias confiscadas.

La perspectiva micro privilegiada busca reconstruir el caso analizando las prácticas rurales/urbanas de gestión en relación a la población esclava confiscada a fin de avanzar en el conocimiento de la cotidianeidad post expulsión de estos actores (ampliamente estudiada bajo el sistema iñiguista). Y plantear hipótesis que contribuyan a definir la naturaleza de los cambios que generaron el deterioro y, luego, hicieron inviable para la gestión porteña rentabilizar las estancias incautadas. La historiografía tradicional señalaba la corrupción de los nuevos gerenciadores como principal factor explicativo del bajo rendimiento productivo de estas unidades agrarias y de la debacle financiera de Temporalidades (Lorandi, 2008). Actualmente, estudios socioeconómicos centrados en el espacio misionero tienden a minimizar el peso de la corrupción de los funcionarios de la Corona, vinculando el declive de la economía misional jesuita posterior al extrañamiento con los límites de la misma en el nuevo contexto de reestructuración política, expansión regional y competencia mercantil impuesto por las reformas (Sarreal, 2014). 
El estudio de los esclavos de las temporalidades del Colegio de Buenos Aires permitirá sumar a estas interpretaciones los matices derivados de una experiencia distinta a la misional e, incluso, diferente a la de las paradigmáticas haciendas del Colegio Máximo de Córdoba, pero al mismo tiempo inserta en el dinámico contexto de expansión productivo-mercantil, valorización de los recursos agrarios y cambio político-institucional del Río de la Plata de fines del siglo XVIII.

\section{"LOS ESCLAVOS DE LOS PADRES": PATRIMONIO CONFISCADO}

El estudio global de la mano de obra forzada empleada en los complejos productivo-mercantiles jesuitas ha señalado que en el litoral la esclavitud era, en relación al Interior del virreinato, menos fundamental - derivándose de ello la aplicación de una política esclavista también menos rígida (Troisi Melean, 2012). La orientación prioritariamente ganadera de la mayoría de las unidades agrarias de la orden explicaba, con matices según el medio local, el menor requerimiento de trabajadores esclavos estables tanto como la estrategia de combinarsuempleo coneldepeones estacionales(Amaral,1989; Djenderedjian, 2011, p. 1-27).

La incautación de los esclavos que integraban el acervo del Colegio de San Ignacio expuso las lógicas de adaptación de un modelo esclavista que había convertido a los trabajadores forzados en la piedra basal de la organización económica de la Compañía. En este contexto regional, el Colegio se destacaba como el mayor propietario de esclavos, funcionando como núcleo articulador de un complejo productivo que complementaba su economía ganadera con la producción agrícola y manufacturera (ladrillos y textiles).

Al momento de la expulsión, los 397 esclavos que poseía el Colegio Grande distribuidos entre la Ranchería de la ciudad y sus establecimientos rurales fueron valuados en 51.372 pesos, representando éstos el 3,2\% del valor total de los bienes confiscados (1.597.369 pesos). El capital inventariado en esclavos constituía el cuarto rubro de inversión, luego de lo registrado en propiedades urbanas, tierras y ganados.

En conjunto el perfil demográfico de estos esclavos poco se aleja del de los esclavos de los jesuitas del Interior: de buen estado sanitario general, organizados en familias y con un marcado equilibrio sexual. Se trataba de una población en crecimiento, cuyo incremento presentaba un ritmo sostenido desde inicios del siglo XVIII con tasas de natalidad altas. La dotación porteña se distingue únicamente por registrar promedios de edad levemente elevados, cercanos a los 30 años entre los esclavos mayoritariamente hombres residentes 
en las estancias. Este indicador, sin embargo, disminuía entre los trabajadores forzados ocupados en los establecimientos de orientación agrícola o mixta agrícola-ganadera (23 y 26 años promedio). Los 122 afroamericanos que contaba con entre 26 y 40 años conformaban el núcleo de la dotación de mano de obra estable en los establecimientos agrarios del Colegio (Tabla 1).

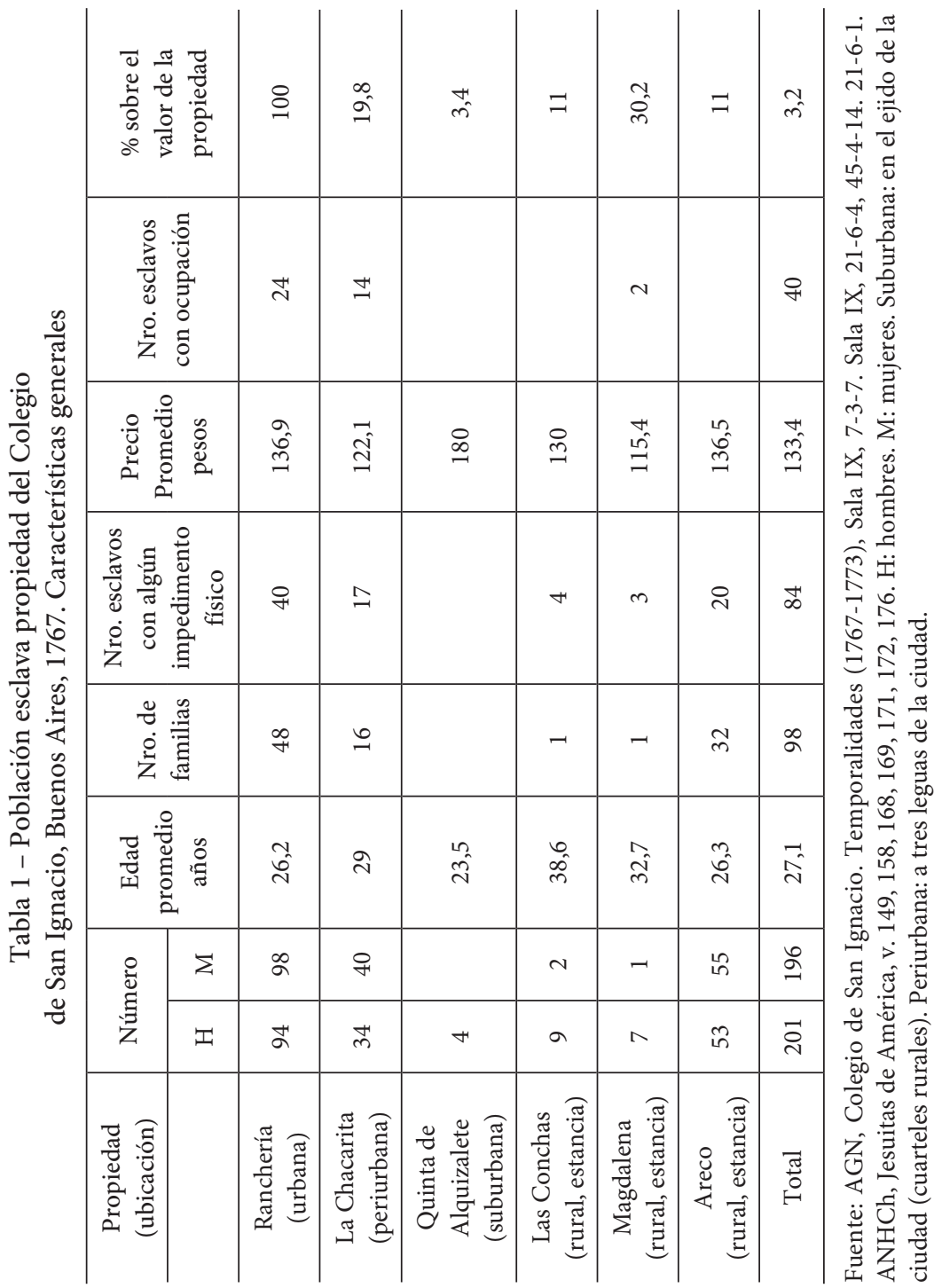


Así, y pese al predominio masculino en las estancias ganaderas, en los números totales se lograba mantener el equilibrio entre los sexos que favorecía las formaciones familiares y la reproducción de la mano de obra. La presencia en los inventarios de niños y criaturas de meses (el 34,7\% de la población esclava poseía en 1767 menos de 16 años, siendo casi la mitad de los mismos menores de 6 años - 66 de 137 individuos) aparecía entonces como el resultado lógico de la política jesuita de crecimiento vegetativo de la población esclava a través del matrimonio cristiano (no aparecen bozales consignados en los inventarios porteños). Efectivamente, identificamos en las propiedades del Colegio Grande 98 grupos familiares que comprendían a 280 personas, es decir el 70,5\% del total de esclavos formaba parte de una familia.

Los inventarios post expulsión relevados muestran que buena parte de esta población servil se hallaba en el Colegio y las "rancherías próximas". Algunos de ellos trabajando en las casas de la villa o en las propias residencias jesuitas. Otros en tránsito ocupados en actividades puntuales (como el traslado de mercancías y animales, por ejemplo) o atendiendo alguna necesidad médica (en la botica del Colegio Grande). Los trabajadores forzados de residencia rural representaban más de un tercio de los justipreciados como parte de las temporalidades porteñas, concentrándose en particular en la estancia de Areco. Los hombres eran ocupados mayoritariamente como capataces y peones ganaderos en las estancias mientras que las "mujeres de trabajo" atendían las quintas y chacras (unidades de producción frutihortícola y cerealera).

El precio en que fue tasado cada uno de ellos no muestra diferencias importantes en lo que respecta a la residencia urbana o rural - reflejando la circulación de los trabajadores al interior del complejo productivo del Colegio. Las tasaciones de los peritos otorgaron al 50\% de los esclavos un valor superior a los 150 pesos, registrando el 33\% entre 180 y 229 pesos (124 personas). Se trata de valores acordes con los de otros inventarios de temporalidades jesuitas e, incluso, cercanos al valor atribuido a esclavos de propietarios particulares del período (Garavaglia, 1999, p. 162).

Los valores asignados presentan variaciones, los esclavos con una ocupación consignada presentaron en promedio un precio algo superior al resto (152 pesos), aunque la valoración de la mitad de los mismos superaba los 179 pesos. Los trabajadores no libres ocupados en algún tipo de actividad artesanal son los más numerosos y los de mayor valor. De residencia urbana, todos ellos fueron censados en la Ranchería, estos albañiles, carpinteros, herreros, zapateros, sastres y músicos constituyen la mano de obra especializada del Colegio y comprenden al 5,6\% del total de esclavos estudiados. A ellos se 
sumaban los 8 "semicalificados" (barberos, boticarios, cocineros, una partera), también esclavos urbanos, que se destacan del resto por su juventud.

Los trabajadores esclavizados con ocupación registrada con menor precio, incluso más bajo que el promedio general, son los empleados en tareas rurales. De los 205 esclavos registrados en las explotaciones agrícolas y ganaderas del Colegio sólo 10 figuran como "capataz" (2), "peón/peón de campo" (6) y "pastor” (2). En la campaña la especialización laboral no aparece como un dato a apuntar: todos los esclavos realizaban todas las faenas rurales. Ellos muestran un perfil opuesto a los artesanos esclavos de residencia urbana: valuaciones bajas (108 pesos), alto promedio de edad (45,6 años) y un comparativamente elevado porcentaje de impedidos por enfermedad o accidentes (3 casos).

Los diversos problemas de salud y discapacidades físicas de los esclavos impactaban directamente en su valorización monetaria. Si bien los inventarios reflejan el buen estado sanitario general de estas dotaciones (en comparación con otras del virreinato), en el caso porteño los esclavos imposibilitados de realizar actividades comprendían el $21 \%$ del total censado en los inventarios (84 personas). Se trataba de hombres accidentados o lastimados durante el desarrollo de las tareas ganaderas preponderantes en las haciendas porteñas: "quebrados" y "lastimados de los brazos y piernas" representan al 30\% de los esclavos registrados con problemas de salud (25 personas). Por cuestiones vinculadas a la moral cristiana, pero también por la inversión económica que representaban, los jesuitas se ocuparon de sus esclavos impedidos destinando la Ranchería del Colegio como residencia de los enfermos y/o lesionados.

El perfil demográfico de la dotación inventariada muestra que las prácticas del Colegio Grande en relación al empleo de la mano de obra esclava supusieron la racionalización del trabajo en función de las características productivas de sus explotaciones agrarias y las de la población esclavizada disponible. Sin embargo, el cuidado de los enfermos, el empleo en tareas menores de esclavos de edad avanzada, las familias y la manutención de niños pequeños, la formación en oficios y la casi ausencia de reventa revela que lo hicieron sin descuidar por ello su atención material y espiritual. Los jesuitas porteños cumplieron, adaptando, con casi todas las disposiciones contenidas en los memoriales e instrucciones que la orden destinaba a los hermanos co-adjuntores a cargo de los fundos de su propiedad (Troisi Melean, 2012; Mayo, 2012; Page, 2008, p. 283-304). 
“Los esclavos del Rey”: LA AdMinistración De Temporalidades

Inmediatamente después de la expulsión de los regulares, el Gobernador Bucareli constituyó en Buenos Aires la Depositaria General de Temporalidades para garantizar el depósito y administración de los bienes, afrontar los gastos de funcionamiento y de pensiones de los jesuitas extrañados. ${ }^{3}$ Para la Depositaria, la manutención y empleo de la dotación de esclavos del Colegio Grande implicó un desafío particular signado por la escasez de recursos, la inexperiencia y/o corrupción de los administradores laicos y el temor constante a posibles levantamientos de los trabajadores negros.

De acuerdo con las instrucciones metropolitanas, el tasador especialista Carlos Sartores se ocupó del avalúo de los esclavos ("sin incluir los inútiles"), insumiéndole la tarea cuatro meses de trabajo. En diciembre de 1767, Bucareli designó como encargado del conjunto de las haciendas al Capitán del Regimiento de Dragones de Buenos Aires Juan Francisco de Somalo. El Ayudante Mayor contaba con el apoyo del capataz Vicente Montoya para asegurar la "conservación y aumento" de estos bienes, en lo que a la población servil se refiere procurar su sustento, impedir las fugas y evitar las muertes a efectos de no paralizar la producción. ${ }^{4}$

Una vez constituida la Junta porteña, se determinó delegar en el recaudador Benito Ruíz el cuidado y mantenimiento del centenar de esclavos residentes en la ciudad, algunos de ellos artesanos que aportaban sus salarios a las arcas del Ramo. Se lo designaba para “sujetar los esclavos, moderar sus diarios”, las Cuentas de Administración de Ruíz y sus posteriores reclamos a Temporalidades constituyen las fuentes documentales a partir de las cuales reconstruimos parte de su tarea. ${ }^{5}$

Durante su gestión, Ruíz se ocupó de garantizar a entre 80 y 122 párvulos y adultos "toda la subsistencia, y atención alimentaria [...] enser vestidos, en dárseles de comer, en ser curados de sus enfermedades". Y proveer los “auxilios semanales, tabaco, yerva, mate, velas, galleta, pan, sal, carne, leña y demás”. El número cambiante de esclavos a su cargo y, en consecuencia, los montos tampoco fijos de los costos de su manutención se explican por la continuidad de una práctica común de la orden: la circulación de la mano de obra servil al interior de los establecimientos agrarios y suburbanos. Y por el mantenimiento de las funciones de la Ranchería como espacio de concentración de los trabajadores en tránsito y de curación de los esclavos provenientes de los distintos "destinos" administrados por la Junta. 
Asimismo, no todos los esclavos en la ciudad se alojaban en la ranchería o dependían del cuidado directo de Ruíz. De acuerdo con el descargo de la Contaduría Principal el administrador omitía que "de los qe residían en la capital, unos estaban en casas particulares, otros al jornal, muchos ambulantes sin destino, y á su propio arbitrio agenciando". Más allá de la intencionalidad de la denuncia, la distribución de los esclavos expropiados "por familias y piezas" entre los vecinos pudientes era un recurso común de las Juntas para tener sujetos y alimentados a los esclavos hasta su remate. En el caso porteño constatamos que, a fin de reducir costos y/u obtener algún ingreso, al menos $24 \mathrm{de}$ los esclavos de los regulares fueron repartidos entre particulares luego de la expulsión.

Recién hacia fines de 1771 fueron reunidos para su retasa, concretándose en los tres años sucesivos la enajenación de 22 de ellos - la mayoría mujeres con niños pequeños aparentemente adquiridos (al contado y a "plazos estipulados") por las mismas familias que los habían alojado probablemente para ocuparlo en trabajos domésticos. Durante la espera del remate, el grupo se sumó a los residentes en la ranchería incrementando los gastos rendidos por Ruíz a Temporalidades.

Las Cuentas de estos gastos anuales permiten un cálculo sólo aproximado del costo de manutención de los esclavos, pues no informan sobre el número preciso de personas a cargo (por lo expuesto, difícil de estimar). Ruíz advertía que incluía en sus balances a "los que vienen repetidamente de las estancias" cuya permanencia transitoria "monta el gasto diario". Incluso aclaraba que los administradores de las estancias suministraban solamente carne a sus esclavos, cubriendo su administración el resto de sus necesidades.

La Tabla 2 resume los montos en pesos erogados en los rubros incluidos en las distintas cuentas del año 1775, uno de los ciclos anuales del período estudiado con registros mensuales completos. Para ese año, Ruíz declaró tener bajo tutela 117 esclavos, dato que fijaría el gasto promedio por esclavo en algo más de 20 pesos anuales. No obstante, este monto se modifica si atendemos a las observaciones que acompañan las rendiciones de cada rubro.

Para este año el administrador registra en sus cuentas gastos por un total de 1.497 pesos 3 reales, dado que excluye de sus cálculos la importante sumada destinada a vestir a los 101 esclavos registrados en la Ranchería, la Residencia y la Calera. Se trata de pagos a siete proveedores quienes suministraron la materia prima para la confección de las camisas, calzones, calzoncillos y ponchos (para los hombres) y de las bayetas, pañetas y lienzos entregados a las 
mujeres. ${ }^{6}$ Temporalidades gastaba en vestir a cada uno de sus esclavos "urbanos" unos 9 pesos anuales.

Tabla 2 - Gastos administración Ruiz, año 1775.

(Expresado en pesos de 8 reales)

\begin{tabular}{c|c}
\hline Rubros & Suma total en pesos \\
\hline Raciones & 772,5 \\
Vestimenta & 928,5 \\
Curaciones & 298 \\
Partos & 2,6 \\
Derechos eclesiásticos & 86,5 \\
Pagos y efectos (esclavos) & 122,5 \\
Herramientas & 16,5 \\
Pago administrador & 200 \\
\hline Total & $2.427,7$ \\
\hline
\end{tabular}

Fuente: AGN, Sala IX, 21-06-03 y 21-08-05 (Años 1775-1776).

Por otro lado sabemos que, del conjunto de los esclavos que temporal o permanentemente estaban bajo la custodia de Ruiz, 83 fueron "de ración" o "número fijo" (por lo que este rubro supone un gasto anual por individuo de poco más de 9 pesos). Cumplidos los tres años de edad, los esclavos recibían una "rasion diaria pr razón de alimentos y subsistencia" que comprendía bizcocho, pan bazo y carne, a lo que se sumaba yerba, tabaco, sal y la leña consumida en la ranchería.

Siguiendo "la costumbre antigua, que observaron los regulares", la dieta cotidiana se ampliaba sólo durante las convalecencias y alumbramientos. De hecho, el rubro "partos" se integra por lo abonado por la compra de 4 botellas de vino y 4 gallinas consumidas en ocasión de los cuatro partos realizados ese año. Asimismo, los enfermos atendidos en la ranchería (el conjunto de los esclavos de Temporalidades) continuaban recibiendo su ración reforzada con carne de carnero, gallinas, pan blanco y arroz (además de velas y un peso extra de leña).

De este modo no sólo en la composición de la ración sino también en las modalidades de su suministro, la administración de Ruíz respetó las instrucciones de los padres en cuanto a la alimentación de los esclavos. ${ }^{7}$ Hasta los fines parecen ser los mismos: "como en este modo de administrarles las raciones no 
se disminuyese, ni aumentase el total del gasto" además de que "de ese modo quedaban contentos conmigo, y trabajaban con gusto".

La necesidad de continuar con ciertas prácticas para asegurar la contención y el trabajo de los esclavos también explica las retribuciones a los albañiles y peones, la compra de sus materiales y herramientas e, incluso, la entrega de efectos a las mujeres. Atendiendo a la costumbre de los regulares, los pagos a oficiales y peones de albañilería y el suministro de jabón a las mujeres se realizaban los días sábado y, pese al incremento de las erogaciones que significaban, también alcanzaba a los trabajadores que venían de las estancias.

No obstante, las cuentas de Ruíz evidencian más que las continuidades el peso que los cambios en la gestión del conjunto de los bienes incautados implicaron para la viabilidad del sostenimiento de los esclavos urbanos (fijos y en tránsito). Porque, pese a contar con ingresos procedentes del trabajo de algunos de los mismos, distribuir a otros entre el vecindario e, incluso, dejar a ciertos esclavos a "su propio arbitrio", quebrada la articulación productiva de los establecimientos agrarios y, con ello, la producción/circulación al interior del complejo jesuita de varios de los bienes consumidos, necesariamente las compras de vestimenta, alimentos y efectos elevaron en mucho el costo de manutención de los esclavos (llegando a representar los dos primeros rubros el 70\% del gasto total). Y a ello debemos sumar el desembolso por servicios o tareas antes desempeñadas por los padres, como las licencias de matrimonios, los derechos de bautismo, "cruz y sepultura" (3,6\% del total) y los honorarios del administrador $(8,2 \%)$. Aun así se trataba de un monto comparativamente aceptable: para Temporalidades de Catamarca el gasto anual por esclavo ascendía a 17 pesos 1 real (Troisi Melean, 2012, p. 126-127) mientras que en las estancias laicas del período éste alcanzaba los 14 pesos (Amaral, 1989).

El costo de manutención de los esclavos continuó siendo una de las principales preocupaciones de Temporalidades, aún cuando su número disminuía constantemente producto de los remates de la fuerza de trabajo forzada y de las ventas de las propiedades rurales. En 1784 Ruíz fue reemplazado, la Junta encargó al nuevo recaudador las mismas tareas asignadas al anterior solicitando que suministre las raciones "observando cuidadosa economía en su repartimiento", organice el trabajo "procurando que ninguno quede ocioso" y gestione atención médica y espiritual. ${ }^{8}$ Para esos años el número de esclavos a cargo de Quiroga en la ciudad rondaba las cien personas.

Las transformaciones se impusieron de manera más acelerada en lo que respecta al trabajo y la vida cotidiana de los esclavos de residencia rural. Con la dirección fragmentada de los establecimientos (que obstaculizaba la 
circulación de los trabajadores forzados), la pérdida y/o deterioro progresivo de la diversidad productiva de los mismos (que impedía el empleo integral de éstos, encareciendo su mantenimiento) los nuevos capataces y administradores laicos consideraban que "los negros y parbulos, solo sirven de gasto".

Sin embargo, la conservación y rentabilidad de las unidades agrarias principalmente dependía de la "sujeción de los esclavos", su productividad y costo de manutención. Si no se venden las haciendas, planteaba en 1770 uno de los administradores laicos, los negros "todos son necesarios; pues [aun] con ellos, es forzoso mantener peones para su trajin y conservación”. Bajo la vigilancia del Intendente de las haciendas secuestradas, se retomó el traslado de esclavos de un establecimiento a otro según las necesidades productivas. Se atendió a que no les faltase su comida y las "otras especies como son tabaco, yerva-mate, vestuario, enfermería", aunque su trabajo y obediencia no derivaba sólo de ello. Así, Juan de San Martín desde la estancia Las Vacas, en agosto de 1770, advertía acerca de la posible de venta de algunos esclavos: "lo que hace alas negritas pequeñas se pueden vender. Nunca será mui conveniente, si esta hacienda, $y$ hubiese de permanecer por cuenta a su Magestad, respecto aque se sujetaran, y servirán con maior gusto los negritos, con la expectativa que se deja entender".

Frente al incremento de las presiones ejercidas desde la Junta para acelerar las enajenaciones, los nuevos gestores cuidaron de conservar las dotaciones necesarias para el sostenimiento de las actividades productivas de las estancias administradas; consideraron enajenables únicamente a esclavos hombres solteros (sin oficio o con mal desempeño en los mismos), a jóvenes y/o mayores de 60 años y en el caso de las mujeres, a unas pocas viudas, de mediana edad y sin hijos a cargo. ${ }^{10}$

Principalmente buscaron asegurar la unidad familiar base de la permanencia del esclavo en la propiedad. Esperando "no sea la mente de esa oficina, cegregar de sus maridos, y aquellos de sus padres, en tan tierna edad”, el administrador de las propiedades de la Residencia de Belén en Montevideo explícitamente señalaba uno de los requisitos centrales para subordinar a su mano de obra. Todos los administradores buscaron evitar la enajenación de las mujeres a fin de "oviar la desunión de los matrimonios", señalando en paralelo "que sus maridos se reservan para el cuidado de las haciendas".

Sin embargo, pese la continuidad de ciertas costumbres y el trato "prudente" ejercido por parte de algunos administradores para con sus trabajadores forzados, el levantamiento no pudo ser evitado. A pocos meses de la expulsión de los regulares, los esclavos de la estancia de Areco protagonizaron un tumulto 
masivo que derivó en fugas, paralización de las actividades ganaderas y pérdida de ganado. El mayor latifundio confiscado a la orden en la campaña porteña, basaba su producción en el trabajo de 108 esclavos encargados de las tareas del establecimiento principal y de los seis puestos de pastoreo que la componían. Esta dotación, principalmente integrada por familias, superaba en mucho el número de esclavizados de cualquier estancia laica del período.

Administrada desde su incautación hasta su venta (1785) directamente por la Junta, durante esta etapa la estancia estuvo bajo la supervisión directa del Capitán Somalo. En líneas generales, su labor arrojó resultados positivos no sólo porque consiguió controlar el levantamiento sino porque además reorganizó la producción obteniendo con ello altos rindes en utilidades. ${ }^{11}$ Frente al manejo de la población servil, su política se orientó a mantener - en la medida de lo posible - el "modo de gobierno de la esclavatura" propio de la orden: "Asi los tenían los PP y yo sigo de la misma forma para evitar desordenes". ${ }^{12}$

Las pautas generales que ordenaban la vida y el trabajo cotidiano de los esclavos en la estancia se conservaron, aunque con algunos cambios. La ranchería cercana a la capilla y al refectorio continuó sirviendo como lugar de morada y descanso, respetándose la distribución de los esclavos al interior de la misma según sexo y condición: "Los casados con sus mujeres tienen su avitacion aparte, y quedan cerrados de noche, y lo mismo sucede á los solteros en otra distante dela de aquellos, y las llaves de todo las recojo yo". Desaparecida la rutina de oración diaria y doctrina así como la obligación dominical de misa, el Capitán también se ocupó de la asistencia religiosa de la fuerza de trabajo a su cargo: "para que no carezcan del pasto espiritual siempre que puedo conseguir algun Religioso le pago la misa a mi costa".

En esta primera etapa de gestión se procuró mantener la unidad de los núcleos familiares y su arraigo local. Retomados los traslados de mano de obra, el administrador dispuso los recursos para que se movilizara a los esclavos con "sus mujeres, criaturas y sus trastos". Se mantuvieron además las asignaciones de labores para las mujeres y la organización del trabajo de los hombres en los puestos de pastoreo establecidos por los padres. Y se respetó al capataz nombrado por los regulares para actuar como mediador/organizador de las diversas faenas de la estancia reconociendo la necesidad (y conveniencia) de contar con un mayoral "de inteligencia y cuidado". Se introdujeron, no obstante, algunas innovaciones que, en el orden de lo simbólico, afectaron la denominación de estos lugares (el puesto Tatú, por ejemplo, pasó a llamarse del Rey “para impresionarles que son sus esclavos”) y, en el práctico, se acentuó la vigilancia continua de los esclavizados allí residentes. 
Pero el sustento diario se garantizaba según la tradición, de acuerdo con Somalo "La razion que han tenido y nunca les á faltado, á sido mas crecida que la que le daban los Padres", alimentación básica que se complementaba con el suministro de yerba y tabaco ("su arraygado vicio") y sal, especies que se repartían "con el mismo arreglo que lo practicaban los PP". También se incluía en ocasiones especiales vino como reemplazo del aguardiente que los padres acostumbraban dar para faenas específicas y celebraciones (ahora monárquicas). Se incluía por supuesto a los esclavos peones de los puestos y se continuaba con la práctica de asegurar ración especial y la asistencia a los niños y enfermos ("a los negritos y enfermos se les da pan").

No obstante, los continuos pedidos de estos productos a Buenos Aires (así como también de ropa de la tierra) prueban las dificultades de una administración que ya no contaba con la red interna de abastecimiento establecida por los regulares. Las prendas "para los negros del Rey" faltaban en la estancia, por ello para continuar con la práctica de los padres ("darles á negras y negros un vestido al año de Bayeta dela tierra, la que solía embiar el Pror de Misiones") se dispuso dar a las mujeres "tarea de lana para que ilen de la qual se tejen ponchos y frezadas para los negros y á este fin he hecho poner una pieza en el telar". Somalo capitalizaba la experiencia en la organización interna del trabajo y de la producción de los establecimientos de la orden, apuntando a conseguir los mismos resultados: "esto menos tendrá que gastar el Rey en vestirlos".

Por lo tanto, muchas de las continuidades identificadas en las prácticas cotidianas en realidad encubren los importantes cambios que afectaron al trabajo de los esclavos en los meses inmediatos al extrañamiento. Estas transformaciones fueron las que, en parte, garantizaron el sostenimiento y la ampliación productiva de la estancia una vez desarticulado el complejo agrario mercantil jesuita. En este contexto, la buena gestión de Somalo fue factible en primer lugar gracias a la reducción de los costos totales de producción y de mantenimiento de la estancia.

El administrador no solo rebajó estos gastos generales sino que además cubrió los mismos con el sólo aporte del centenar de arrendatarios agrícolas que poblaban las tierras desde tiempos de los jesuitas: "Con esta contribución ay para el gasto que se ofrece aquí que no será el que tenían los PP porque hé rebajado por haverme parecido excesivo". Se despidió entonces a los peones asalariados y al capataz "paysano", reemplazados por negros e indios de las misiones (éstos solo útiles para algunas tareas "por no ser de á cavallo"), se abandonó la siembra y se espaciaron los rodeos, pero se incrementó la producción de cueros 
destinando a esta tarea únicamente a los trabajadores forzados de la estancia cuyo número se redujo por las huidas producto del levantamiento.

Consecuentemente, se incrementó la cantidad y el tipo de trabajo exigidos a los esclavos ("para todo aquello que sepueda hacer con los negros si V.E. gusta, haré que travajen"). A las tareas ganaderas habituales se sumaron otra nuevas (como el hilado) o antes realizadas por afroamericanos pertenecientes a otros establecimientos del complejo jesuita prioritariamente orientados a producciones especificas ("haré que corten adobe y los cuezan"). Aún con menos esclavos se intensificaron y realizaron nuevas faenas, en virtud de una política orientada a "que medie la menor ociosidad en aprovechar el tiempo..." (de la mano de obra esclavizada).

La lógica que guiaba el trato de la fuerza laboral servil fue maximizar su eficiencia, el trabajo de los nuevos esclavos del rey debía generar las mismas e incluso mayores riquezas que las que producían para la orden. Todas sus acciones en la gestión de la estancia se encaminaron a "que S M tenga las utilidades mas ventajosas que se puedan sacar". Para conseguirlo, el administrador consideraba necesario rectificar la conocida "altanería" e "insolencia" de los esclavos de los expulsos, dejando en claro su nueva situación en este contexto de renegociación de fuerzas.

Justamente, el tumulto de septiembre de 1767 en Areco se originó como respuesta a los cambios en el sentido otorgado al trabajo de los esclavos. A meses de la expulsión, las prácticas tradicionales que pautaban el trabajo cotidiano de los mismos comenzaron a flexibilizarse (sin cambiar sus formas) para introducir novedades que implicaban más trabajo y deterioro de sus condiciones de vida. Sin embargo, los esclavos no se rebelaron denunciando estos excesos sino acusando al encargado de Temporalidades de haber "venido a destruir el trabajo de ellos". ${ }^{13}$

Según informes oficiales, el levantamiento se inició por la negativa de un esclavo del Puesto de Mulas a obedecer la orden impartida por el administrador de recoger los animales para su envío a Buenos Aires. Pronto este incidente se tornó una movilización colectiva, los rebeldes pregonaban que no iban a permitir sacar ganado de la estancia "por que [NO] era del Rey ni le havia costado de suplata". Los esclavos confiscados se negaban a reconocerse como propiedad del nuevo amo y con ello otorgarle derechos sobre su labor. 


\section{CONSIDERACIONES FINALES}

Mucho se ha escrito sobre los esclavos de los jesuitas. Desde la perspectiva de la historia económica, los estudios pioneros interesados en reconstruir el funcionamiento de las haciendas de la Compañía han demostrado cómo la utilización sistemática e integral de la población esclava fortalecía la diversificación productiva y la inserción mercantil de sus establecimientos agrarios, al tiempo que reducía los costos de su manutención y transfería parte del producto de su trabajo a la remuneración del trabajador libre rebajando sus salarios. (Albores; Mayo; Sweeney; 1994, p. 17-36; Troisi Melean, 1998, p. 115-142). Las investigaciones también clásicas sobre el mundo rural rioplatense tardío colonial subrayaron, en paralelo, el papel estabilizador de la fuerza de trabajo esclavizada y la lógica económica de su empleo articulado con el estacional asalariado de peones, en un contexto de expansión de la producción pecuaria, escases de mano obra y circulante (Amaral, 1989; Mayo, 1994).

El análisis del perfil demográfico de la población esclava confiscada a los jesuitas de Buenos Aires y la reconstrucción de las políticas de sustento y sujeción aplicadas por la administración laica en el período inmediatamente posterior al extrañamiento permiten sumar al panorama general del virreinato rioplatense las singularidades de las prácticas asociadas a la inserción de la orden en la expansiva economía agraria del litoral del último tercio del siglo XVIII. Y avanzar en la consideración del impacto que en la cotidianeidad de los actores involucrados supusieron las medidas desamortizadoras del reformismo borbónico.

Los jesuitas porteños adaptaron las estrategias generales de utilización del trabajo esclavo propias de la orden a las condiciones de producción extensiva de las estancias. Para hacerlo, delinearon un esquema de complementariedad que les permitía rentabilizar el uso de la mano de obra servil igual que en los colegios del Interior, aunque a partir de una inversión proporcionalmente menor. Los esclavos constituían aquí también la piedra basal de la organización económica, siendo la clave de la rentabilidad de las estancias (unidades matrices del complejo productivo-mercantil que sostenía las crecientes actividades catequísticas).

El Colegio en la ciudad retroalimentaba esa estrategia albergando en su ranchería los esclavos en tránsito y otorgando residencia sólo a aquellos necesarios para el servicio en la chacra y/o la elaboración manufacturera/artesanal. De esta manera, el Colegio maximizó su inversión patrimonial en el rubro esclavatura orientado el trabajo de sus esclavos en función de los ciclos de la 
demanda ampliada derivada de la expansión de la producción pecuaria, el sostenido crecimiento demográfico (rural/urbano) de Buenos Aires y el incremento acelerado del tráfico del complejo portuario rioplatense tardío colonial (Gelman, 2012, p. 85-122; Moraes, 2014, p. 22-33).

Sin embargo, estos criterios económicos de organización productiva (que efectivamente reducían los costos en el mediano plazo) se asociaban a ciertas prácticas en el tratamiento de la población esclava que sólo adquirían sentido en la lógica de la orden subordinadas a su misión apostólica. La legislación de la Corona y de la Iglesia reconocía a los esclavizados derechos (Levaggi, 1973, p. 83-159); sin embargo fue la Compañía quien asumió un ministerio especial respecto a los mismos prestando particular atención a la doctrina. Los esclavos de las haciendas de los jesuitas no eran un mero instrumento de trabajo: el paternalismo iñiguista los situaba en el plan de Dios, los regulares empleaban el trabajo de sus siervos para facilitar la redención de los indios y la suya propia (De Borja Medina, 2005, p. 83-122; Tardieu, 2015, p. 17-27).

La esclavitud de los negros, imprescindible en este esquema para la explotación de las estancias, se inscribía entonces en la visión espiritualista de la Compañía. Llevar adelante esta tarea suponía aliviar las condiciones de vida de los trabajadores serviles y facilitar el acceso a la enseñanza cristiana para garantizarles así la libertad de sus almas. Buen tratamiento que no eliminaba, sino todo lo contrario, el fuerte sentido jerárquico ni el estricto control disciplinario aplicado por los regulares sobre sus dotaciones. Por ello, la política esclavista jesuita requería de una atención permanente, de vigilancia local y de coordinación centralizada (tal como lo evidencian las instrucciones impartidas a los hermanos co-adjuntores).

Este sistema, que en el caso del Colegio de Buenos Aires implicaba además de la manutención, la sujeción y dirección de cerca de 400 personas, se reveló insostenible para una administración laica guiada por otros intereses. Primero, la gestión de la Depositaría y posteriormente la de la Junta porteña desarticularon la base económica del empleo "eficiente" de la mano de obra forzada al fragmentar la administración productiva del complejo agrario confiscado y luego, urgida por el déficit de sus cuentas, propiciar la venta individual (o grupal) de los esclavizados - bienes de rápida enajenación. En paralelo, en una dinámica similar a la estudiada para juntas municipales y provinciales del Interior, en menos de una década la administración porteña traspasó a terceros beneficiarios (mediante venta y/o arriendo) el gerenciamiento productivo de los bienes incautados, incluidas las dotaciones de esclavos - aspecto que impide comparaciones más amplias. 
Sin embargo, durante la primera etapa de Temporalidades cuando ésta asume la explotación directa de las estancias hallamos que la producción en las mismas fue posible en gran parte por la aparente continuidad de las prácticas ignacianas de sujeción de la fuerza de trabajo esclavizada (aunque los fines de la administración eran otros). En un escenario en el que el equilibrio de poder que regulaba las relaciones amo-esclavo todavía era inestable, a fin de mitigar la tensión los encargados (faltos de recursos coercitivos) recurrieron a los modos acostumbrados de organización y empleo de la "esclavatura". Las fisuras aparecieron cuando las presiones ejercidas desde Buenos Aires en pos de mayores beneficios inmediatos obligaron a los cambios.

Las fallas en el abastecimiento de las necesidades básica de alimentación y vestimenta de la mano de obra servil se conjugaron entonces con los mayores requerimientos de productividad y con un tratamiento cotidiano que se orientaba a igualarlos con el resto de los esclavos de la región. Probablemente, muchas de las carencias denunciadas ya las sufrían los esclavos durante la administración de los regulares, pero el trato dispensado por los mismos había producido entre ellos un sentido de pertenencia, basado en el respeto de esos "derechos", difícil de reemplazar.

Para los esclavos de los padres devenidos en esclavos realengos, el extrañamiento se tradujo entonces en algo más que la pérdida progresiva de ciertos beneficios materiales, el sentido de su trabajo y con él el de su identidad se vio modificado. Por ello reiteraban que ellos no eran esclavos del rey sino de los padres, que el fruto de su labor aún les pertenecía. Cuando se amotinaron lo hicieron en defensa de la propiedad de los padres y, con ello, de un sistema de trabajo que regulaba su existencia a partir de criterios no exclusivamente materiales.

Para los administradores locales del reformismo borbónico la defensa de los intereses reales hacía que la costosa manutención de los negros sólo tuviera sentido en relación a una mayor explotación de su trabajo. Esta visión utilitaria y cortoplacista del empleo de la mano de obra forzada los llevó primero a denunciar la insolencia, soberbia y ociosidad de los esclavos confiscados y, luego, a incrementar y diversificar las tareas a ellos asignadas. Posteriormente, los mismos argumentos justificaron la política de ventas.

Sin embargo, las subastas públicas de estos esclavos por "pieza" o "lotes" no resultaron para la Junta fuente de ingresos significativos. La administración de Buenos Aires concretó, entre 1768 y 1771, la subasta en almoneda pública de sólo un tercio de los esclavos propiedad del San Ignacio. La mayor parte de los esclavos de la orden fue transferida a particulares como bienes incluidos en las estancias vendidas indivisas a la élite porteña beneficiada por el reformismo 
borbónico. Finalizada la administración directa de Temporalidades, las rupturas en relación al tratamiento de los trabajadores esclavos que "habían sido de los jesuitas" serían entonces todavía más radicales.

\section{REFERENCIAS}

ALBORES, Oscar; MAYO, Carlos; SWEENEY, Judith. Esclavos y conchabados en la estancia de Santa Catalina, Córdoba (1764-1771). Notas para su estudio. In: MAYO, Carlos (comp.). La historia agraria del interior: haciendas jesuíticas de Córdoba y el Noroeste. Buenos Aires: CEAL, 1994. p. 17-36.

AMARAL, Samuel. Producción y mano de obra rural en Buenos Aires colonial: la estancia de Clemente López Osornio, 1785-1795. Buenos Aires: Instituto T. Di Tella Centro de Investigaciones Sociales, 1989.

ANDRÉS-GALLEGO, Juan. Esclavos de Temporalidades (El Tucumán, 1768): posibilidades de una fuente documental. Hispania sacra, v. 48, n. 97, p. 231-260, 1996.

ANDRÉS-GALLEGO, Juan. La esclavitud en la monarquía hispánica: un estudio comparativo. In: ANDRÉS-GALLEGO, Juan (dir.). Tres grandes cuestiones de la historia de Iberoamérica: ensayos y monografías, Iberoamérica: Afroamérica, la tercera raíz: Impacto en América de la expulsión de los jesuitas. España: Mapfre Tavera, 2005.

CANDIOTI, Magdalena. Renovación y re-afirmación de los estudios sobre esclavitud y emancipación en el Río de la Plata. Estudios sociales, v. 53, p. 95-100, jul./dic. 2017.

CILIBERTO, María Valeria. De los jesuitas a la administración de las Temporalidades. El patrimonio de la Compañía de Jesús y la fuerza de trabajo esclava en el Río de la Plata (fines del siglo XVIII). Cuadernos de Historia, n. 44, p. 29-56, jul. $2016 \mathrm{a}$.

CILIBERTO, María Valeria. La cesión y venta de los bienes de los jesuitas en la campaña de Buenos Aires y la Banda Oriental de fines del siglo XVIII. Topoi - Revista de História, Rio de Janeiro: UFRJ, v. 17, n. 32, p. 109-133, enero/jun. $2016 \mathrm{~b}$.

CUSHNER, Nicolas. Jesuit Ranches and the Agrarian Development of Colonial Argentina. 1650-1767. New York: State University of New York Press, 1983.

DE BORJA MEDINA, F. S.J. El esclavo: ¿bien mueble o persona? Algunas observaciones sobre la evangelización del negro en las haciendas jesuíticas. In: MARZAL, Manuel; NEGRO, Sandra (comp.). Esclavitud, economía y evangelización: las haciendas jesuitas en la América. Lima: PUCP, 2005. p. 83-122.

DJENDEREDJIAN, Julio. Optimizando recursos escasos en un área de frontera. La opción por la mano de obra esclava en grandes estancias entrerrianas de tiempos coloniales. Quinto Sol, v. 15, n. 2, p. 1-27, 2011.

GARAVAGLIA, Juan Carlos. Pastores y labradores de Buenos Aires: una historia agraria de la campaña bonaerense 1700-1830. Buenos Aires: Ed. de la Flor, 1999. 
GELMAN, Jorge. La economía de Buenos Aires. In: FRADKIN, Raúl (dir.). Historia de la Provincia de Buenos Aires. Tomo 2: De la conquista a la crisis de 1820. Buenos Aires: Unipe: Edhasa, 2012. p. 85-122.

LAMBORGUINI, Eva; GELER, Lía; GUZMAN, Florencia. Los estudios afrodescendientes en Argentina: nuevas perspectivas y desafíos en un país "sin razas". Tabula Raza, n. 27, p. 67-101, jul./dic. 2017.

LEVAGGI, Abelardo. La condición jurídica del esclavo en la época hispánica. Revista de Historia del Derecho, n. 1, p. 83-159, 1973.

LORANDI, Ana María. Poder central, poder local: funcionarios borbónicos en el Tucumán colonial. Un estudio de antropología política. Buenos Aires: Prometeo, 2008.

MAYO, Carlos (comp.). La historia agraria del interior: haciendas jesuíticas de Córdoba y el Noroeste. Buenos Aires: Ceal, 1994.

MAYO, Carlos. Memoriales e instrucciones para el manejo de estancia en el noroeste argentino. Mar del Plata: Grupo Sociedad y Estado: FH-UNMdP, 2012.

MORAES, María Inés. Tendencias y coyunturas agrarias del Litoral rioplatense, 17601800. Investigaciones de Historia Económica, Montevideo, v. 10, p. 22-33, 2014.

MORNER, Magnus. Actividades políticas y económicas de los jesuitas en el Río de la Plata. Buenos Aires: Hyspamerica, 1968.

PAGE, Carlos. Reglamento para el funcionamiento de las haciendas jesuíticas en la Antigua Provincia del Paraguay. DIECIOCHO, v. 32, n. 2, p. 283-304, otoño 2008.

PUNTA, Ana Inés. Venta de los esclavos de las haciendas jesuíticas de Córdoba después de la expulsión (1767-1772). Algunos avances. Cuadernos de Historia. Serie economía y sociedad, Córdoba, n. 16/17, p. 66-112, 2016.

SARREAL, Julia. The Guaraní and Their Missions: A Socioeconomic History. Stanford, CA: Stanford University Press, 2014.

TARDIEU, Jean Pierre. Los esclavos de los Jesuitas del Río de la Plata (Paraguay), 1767: Historia de una dramática regresión. Saarbrücken: Ed. Académica Española, 2012.

TARDIEU, Jean Pierre. Semiología del "silencio" de los jesuitas ante la esclavitud de los Negros en Hispanoamérica. In: GONZALES, Donato Amado; FORNIES CASALS, José; NUMHAUSER, Paulina. Escrituras silenciadas: poder y violencia en la Península Ibérica y América. Alcalá de Henares: Ed. Universidad de Alcalá, 2015. p. 17-27.

TELESCA, Ignacio. Tras los expulsos: cambios demográficos y territoriales en el Paraguay después de la expulsión de los jesuitas. Asunción: Ceaduc, 2009.

TROISI MELEAN, Jorge. El oro de los jesuitas: la compañía de Jesús y sus esclavos en la argentina colonial. S. 1.: Ed. Académica Española, 2012.

TROISI MELEAN, Jorge. Una residencia, dos sistemas: el hospicio jesuita de Catamarca bajo la administración religiosa y laica (1743-1769). Andes, Salta, v. 9, p. 115-142, 1998. 


\section{NOTAS}

${ }^{1}$ Agradezco los valiosos comentarios realizados por los evaluadores anónimos de la Revista.

${ }^{2}$ Estudios locales que recuperaron las condiciones de vida, experiencias y representaciones de los esclavizados cuestionaron las visiones tradicionales que destacaban la naturaleza "benigna" del sistema esclavista local y afirmaban la supuesta singularidad étnico-racial regional. Tempranamente estos aportes se asociaron a una también renovada historia rural, que reubicó el rol de la fuerza de trabajo forzada en la economía agraria tardío colonial y temprano independiente. Actualmente, la reflexión gira en torno a la construcción de las categorías raciales coloniales y poscoloniales, el proceso de abolición y las múltiples transformaciones que involucraron a estos actores durante la independencia (en dialogo con la historia de los sectores populares).

${ }^{3}$ En 1769 se instituyeron las Juntas de Temporalidades, creándose luego diez juntas superiores y otras subordinadas. La Junta Superior Provincial de Buenos Aires comprendía cuatro provincias, las cuales tenían sus respectivas Juntas Municipales. De la primera dependía la de Buenos Aires, Corrientes, Santa Fe y Montevideo. La Depositaría fue suprimida en 1771.

${ }^{4}$ AGN, Sala IX, 7-3-7. AGN, Sala IX, 21-08-03.

${ }^{5}$ AGN, Sala IX, 21-06-03, 21-08-03 y 21-08-05. El siguiente análisis remite a estas fuentes documentales, salvo específica referencia.

${ }^{6} \mathrm{AGN}, 21-06-03$. Cuenta comprov.te $N^{o} 14$ de los gastos causados de las vestimentas de los esclavos en todo el año 1775 (Año 1776).

${ }^{7}$ Instrucciones a los Hermanos Jesuitas Administradores de Haciendas (manuscrito Mexicano del siglo XVIII), Cap. III. "De lo que han de guardar en el buen gobierno de los esclavos donde los hay" (CHEVALIER, 1950, p. 61-83).

${ }^{8}$ AGN, Sala IX, 21-05-06.

${ }^{9}$ ANHCh, Jesuitas 156, Pieza 1, fs. 1-40. Los establecimientos agrarios administrados directamente por Temporalidades concentraban sus gastos principalmente en el sustento de sus esclavos (CILIBERTO, 2016b).

${ }^{10}$ ANHCh, Jesuitas 156, Pieza 1, fs. 1-40.

${ }^{11}$ AGN, Sala IX, 21-5-9.

${ }^{12}$ AGN, IX, 1-4-1. Comandancia de Frontera de San Antonio de Areco (1757-1809). El siguiente análisis remite a estas fuentes documentales, salvo específica referencia.

${ }^{13}$ AGN, IX, 1-4-1. Comandancia de Frontera de San Antonio de Areco (1757-1809). Estancia del Rey, Areco, 5 agosto y 4 oct. 1767.

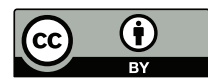

